\title{
Development of Appypie-based Android Application as a Learning Media about Alga in Monera and Protista Course for Students Majoring in Biology Education
}

\section{Pengembangan Aplikasi Android Berbasis Appypie sebagai Media Pembelajaran Taksonomi Monera dan Protista Materi Alga Bagi Mahasiswa Pendidikan Biologi}

\author{
Harlis $^{1}$., Retni. S. Budiarti ${ }^{2}$ \\ ${ }^{1,2)}$ Dosen Pendidikan Biologi Fakultas Keguruan dan Ilmu Pendidikan \\ Universitas Jambi \\ Email: ${ }^{1}$ harlisbiologi@yahoo.co.id ${ }^{2}$ rsb_nugraha@yahoo.co.id
}

\begin{abstract}
Student habit that tends to use gadgets as primary needs is commonly found in universities. This habit contributes to various problems occurred due to gadget misuse. In order to overcome the problems, lecturers as the educators are required to create innovations to facilitate students so they could learn anywhere and anytime. Therefore, technology needs to be used practically to create a better education. The advancement of technology could be used in learning process for developing both learning instrument and media. This research aims to produce Appypie-based Android Application as a Learning Media about Alga in Monera and Protista Course that is appropriate to use by Biology Education students. This study is a type of research and development. The steps in developing an Appypie-based android application include: Decide, Design, Develop and Evaluate (DDD-E). The feasibility test covers the level of validity and practicality of Appypie-based android applications as a learning media. This study results in a content validity level of 3.78 (very valid), media validation of 3.6 (very valid) and media practicality of 3, 74 (very practical). Based on the results, this is suggested for further research and development in order to develop learning media in other subjects, according to the basic competencies taught.
\end{abstract}

\section{Keywords: Development of android applications, Appypie and learning media}

Abstrak. Gaya hidup mahasiswa yang cenderung menjadikan gadget sebagai kebutuhan pokok dan sangat mudah dijumpai di perguruan tinggi.Sehingga berbagai permasalahan timbul akibat penggunaan gadget yang tidak tepat guna.Untuk menjawab permasalahan yang ditimbulkan dari pesatnya kemajuan teknologi yang semakin berkembang, dosen sebagai tenaga pendidik harus menciptakan inovasi-inovasi terbaru untuk menfasilitasi mahasiswa agar dapat belajar kapan saja dan dimana saja tanpa dibatasi ruang dan waktu dengan mudah dan terjangkau.Sehingga teknologi harus dimanfaatkan semaksimal mungkin untuk menciptakan pendidikan yang lebih baik. Kecanggihan teknologi dapat digunakan dalam proses pembelajaran baik dalam mengembangkan perangkat pembelajaran maupun media pembelajaran.Tujuan penelitian ini untuk menghasilkan Aplikasi Android Berbasis Appypie sebagai Media Pembelajaran Taksonomi Monera dan Protista Materi Alga yang layak digunakan bagi mahasiswa Pendidikan Biologi.Penelitian ini menggunakan jenis penelitian Research and Development (penelitian dan pengembangan). Langkah-langkah dalam memgembangkan aplikasi android berbasis Appypieini dilakukan dengan mengikuti model pengembangan Decide, Design, Develop, Evaluate (DDD-E). Uji kelayakan meliputi tingkat kevalidan, dan kepraktisan aplikasi android berbasis Appypie sebagai media pembelajaran.Penelitian ini menghasilkan Media aplikasi androidberbasis appypie sebagai media pembelajaran taksonomi monera dan protista materi alga dengan tingkat kevalidan dari validasi materi 3,78 (sangat valid) dan tingkat kevalidan dari validasi media 3,6 (sangat valid) serta tingkat kepraktisan media dengan nilai 3,74 (sangat praktis).Berdasarkan hasil penelitian disarankan untuk 
penelitian dan pengembangan selanjutnya agar dapat mengembangkan media pembelajaran pada materi yang lainnya, sesuai dengan kompetensi dasar yang diajarkan.

Kata kunci: Pengembangan aplikasi android, Appypie dan media pembelajaran

\section{PENDAHULUAN}

Kemajuan teknologi dan informasi (TIK) tidak dapat terlepas dari berbagai kehidupan manusia termasuk dalam dunia pendidikan.Penggunaan teknologi di dunia pendidikan tidak sulit dijumpai.Segala aktifitas di instansi pendidikan baik sekolah maupun perguruan tinggi telah banyak yang memanfaatkan kecanggihan teknologi itu sendiri.Salah satunya adalah dalam mencari materi pembelajaran yang dapat dengan mudah ditelunsuri melalui internet.Kemajuan teknologi dan informasi telah mengubah cara orang dalam belajar. Kecanggihan teknologi memberikan tanggapan besar dalam memainkan peran penting mencerdaskan anak bangsa. Sehingga teknologi harus dimanfaatkan semaksimal mungkin untuk menciptakan pendidikan yang lebih baik. Kecanggihan teknologi dapat digunakan dalam proses pembelajaran baik dalam mengembangkan perangkat pembelajaran maupun media pembelajaran.

Pendidikan yang baik didukung oleh beberapa faktor yang menunjang proses pembelajaran. Diantara faktor-faktor itu adalah kelengkapan buku pembelajaran, ketepatan kurikulum serta penggunaan media yang tepat guna.Namun tampilan buku yang tidak menarik serta volume buku yang berat menyebabkan mahasiswa menjadi malas untuk membaca. Selain itu, gaya hidup mahasiswa yang cenderung menjadikan gadget sebagai kebutuhan pokok dan sangat mudah kita jumpai di perguruan tinggi. Sehingga berbagai permasalahan timbul akibat penggunaan gadget yang tidak tepat guna. Untuk menjawab permasalahan yang ditimbulkan dari pesatnya kemajuan teknologi yang semakin berkembang, dosen sebagai tenaga pendidik harus menciptakan inovasi-inovasi terbaru untuk menfasilitasi mahasiswa agar dapat belajar kapan saja dan dimana saja tanpa dibatasi ruang dan waktu dengan mudah dan terjangkau.Sehingga mahasiswa lebih tertarik untuk belajar. Taksonomi monera dan protista merupakan salah satu mata kuliah wajib pada program studi pendidikan biologi. Salah satu materi dalam mata kuliah ini yang dianggap sulit oleh mahasiswa yaitu materi Alga. Hal ini dikarenakan cakupan materi yang sangat banyak sementara dalam proses pembelajaran bahan ajar yang digunakan hanya buku teks dan beberapa media seperti powerpoint. Sehingga hasil belajar mahasiswa masih tergolong rendah.

Sehubung dengan permasalahan tersebut, penelitian ini memberikan satu solusi inovatif yang efektif dan dapat digunakan sebagai media pembelajaran. Adapun inovasi yang akan dikembangkan yakni media pembelajaran berbasis teknologi dan komunikasi (TIK), dengan alasan mahasiswa yang telah akrab dengan dunia teknologi menjadikan media ini dapat diterima dengan mudah dan menyenangkan untuk digunakan oleh mahasiswa dalam belajar (Asyhar, R., 2012). 
Media pembelajaran ini diwujudkan dalam bentuk aplikasi android. Konsep pembelajaran dengan menggunakan aplikasi android diharapkan akan membantu dosen dalam memenuhi tuntutan kemajuan teknologi serta menjadikan media-media pembelajaran lebih menarik yang dikemas dalam bentuk aplikasi android (Intania., 2012). Media pembelajaran dalam bentuk aplikasi android merupakan media pembelajaran yang mudah digunakan dan praktis. Dengan mengkombinasikan gambar, teks, warna serta video maupun animasi dalam materi belajar akan membuat siswa tertarik untuk membaca dan mempelajarinya. Media ini berupa software atau aplikasi yang dapat dibuka dan di simpan di smartphone dengan merek apapun dengan catatan harus menggunakan sistem operasi android (Amin.A.K., dan Mayasari. N, 2015).

\section{METODE PENELITIAN}

Penelitian ini menggunakan jenis penelitian Research and Development (penelitian dan pengembangan). Menurut Putra, N. (2012 Langkah-langkah dalam memgembangkan media aplikasi android berbasis Appypieini dilakukan dengan mengikuti model pengembangan Decide, Design, Develop, Evaluate (DDD-E). Prosedur yang digunakan untuk menghasilkan media pembelajarandengan menggunakan softaware yang dapat dibuka secara online di situs www.Appypie.com. Model yang digunakan adalah DDD-E.Peneliti menggunakan model DDD-E dikarenakan model ini sederhana dan mudah dipelajari serta strukturnya yang sistematis dan sesuai untuk penggembangan media pembelajaran yang bersifat multimedia. Menurut Tegeh, M,. Jampel, I.N, \& Pudjawan, K. (2014) "salah satu model desain pembelajaran yang dapat digunakan mengembangkan multimedia pembelajaran adalah model DDD-E." Berdasarkan model DDD-E prosedur penelitian pengembangan dilaksanakan dengan tahap-tahap Decide (menentukan), Design (desain), Develop (mengembangkan), dan Eavluate (evaluasi).

\section{a. Subjek Ujicoba}

Subjek ujicoba dalam penelitian pengembangan ini adalah mahasiswa semester 5 program studi pendidikan biologi.Ujicoba ini dilakukan untuk melihat praktikalitas dan efektivitas media aplikasi android berbasis Appypie yang dikembangkan.Uji coba produk ini dimaksudkan untuk mengumpulkan data tentang kualitas media pembelajaran dan untuk melihat respon mahasiswa terhadap media yang telah dikembangkan.Data-data tersebut digunakan untuk memperbaiki dan menyempurnakan media pembelajaran aplikasi android yang merupakan produk dalam penelitian ini.

\section{b. Jenis Data}

Data dalam penelitian ini berupa data Kuantitatif dan kualitatif. Data pertama berupa hasil validasi media aplikasi android berbasis Appypie yang dikembangkan.Data 
kedua diperoleh pada pelaksanaan ujicoba. Pada ujicoba ini diambil data berupa respon mahasiswa terhadap media yang dikembangkan.

\section{c. Instrumen Pengumpulan Data}

Instrumen yang digunakan dalam penelitian ini berupa angket dengan menggunakan skala Likert diberikan ke ahli media dan ahli materi serta guru dan siswa. Instrumen pengumpulan data pada penelitian pengembangan ini adalah instrumen kevalidan dan kepraktisan.

\section{d. Teknik Analisis Data}

Setelah data diperoleh, selanjutnya adalah menganalisis data tersebut. Data yang akan diperoleh dalam penelitian ini adalah data kualitatif. Data kualitatif berupa lembar validasi dari ahli yang berisi tanggapan, saran dan masukan.Dimana tanggapan, saran, dan masukan dari ahli tersebut dipertimbangkan dan dianalisis untuk perbaikan produk (Riduwan, 2013).

\section{HASIL PENGEMBANGAN}

Hasil penelitian dan pengembangan ini berupa tingkat kevalidan dan kepraktisan media Aplikasi Android yang dibuat dengan menggunakan Appypie pada pembelajaran taksonomi monera dan protista materi alga.

\section{a. Validasi Materi}

Validasi materi juga dilakukan untuk melihat kevalidan materi pada media aplikasi android berbasis appypie pada materi Alga divisi chlorophyta.Pada penelitian dan pengembangan ini validasi materi dilakukan sebanyak dua kali.Penilaian isi materi oleh validator materi di dapat data kuantitatif sebagai berikut:

Tabel 3.1 Hasil Validasi Materi

\begin{tabular}{|c|c|c|}
\hline Deskriptor & $\begin{array}{l}\text { Hasil Validasi } \\
\text { I }\end{array}$ & $\begin{array}{l}\text { Hasil Validasi } \\
\text { II }\end{array}$ \\
\hline $\begin{array}{l}\text { 1. Materi yang disajikan sesuai dengan silabus dan RPS pada } \\
\text { kurikulum pendidkan biologi }\end{array}$ & 4 & 4 \\
\hline $\begin{array}{l}\text { 2. Materi yang disajikan sesuai dengan standar kompetensi } \\
\text { pada kurikulum pendidikan biologi }\end{array}$ & 3 & 4 \\
\hline 3. Runtutan materi yang disajikan sudah baik & 2 & 3 \\
\hline 4. Keakuratan ilustrasi dan contoh yang digunakan & 3 & 4 \\
\hline $\begin{array}{l}\text { 5. Cakupan materi sesuai dengan tingkatan kemampuan } \\
\text { mahasiswa }\end{array}$ & 3 & 4 \\
\hline 6. Kesesuaian materi dengan perkembangan jaman & 4 & 4 \\
\hline $\begin{array}{l}\text { 7. Materi yang disajikan mendorong mahasiswa untuk } \\
\text { mencari informasi }\end{array}$ & 4 & 4 \\
\hline 8. Materi yang disajikan menarik mahasiswa dalam belajar & 4 & 4 \\
\hline 9. Cakupan materi dapat tersampaikan dengan baik & 3 & 3 \\
\hline Jumlah & 30 & 34 \\
\hline
\end{tabular}


Berdasarkan Tabel 3.1, dapat dilihat bahwa rata-rata skor hasil validasi I yaitu: $R=\frac{30}{1(9)}=$ 3,33.Hasil ini menunjukkan bahwa media termasuk dalam kategori valid.Hasil vakidasi menunjukan perlu adanya validasi lebih lanjut terkait materi yang ada pada Aplikasi Android Berbasis Appypie.Hal ini terlihat ada point dari deskriptor yang manjadi penilaian masih memperoleh nilai 2.Untuk itu dilakukan validasi ke dua. Hasil validasi kedua pada tabel 4.1 menunjukan hasil dengan rata-rata $R=\frac{34}{1(9)}=3,78$. Hasil rerata ini menujukkan bahwa media berada pada kategori sangat valid dari segi materi.

Validasi media dilakukan sebanyak dua kali.Bagian-bagian yang harus diperbaiki adalah menu yang terdapat di bawah sebaiknya dipindahkan kebagian kanan dan berjajar agar lebih mudah dimengerti.Video pembelajaran harus dipilih sesuai dengan materi alga divisi chlorophyta serta video yang digunakan harus jelas.Berdasarkan hasil validasi pertama tersebut pengembang melakukan pembuatan ulang produk yang telah direvisi sesuai dengan saran yang telah diberikan oleh validator.Adapun hasil validasi media dapat dilihat sebagai berikut:

\section{Tabel 3.2 Hasil Validasi Media}

\begin{tabular}{|c|c|c|}
\hline Deskriptor & $\begin{array}{l}\text { Hasil Validasi } \\
\text { I }\end{array}$ & $\begin{array}{c}\text { Hasil Validasi } \\
\text { II } \\
\end{array}$ \\
\hline 1. Media yang digunakan rapi dalam susunan serta penataanya. & 2 & 3 \\
\hline 2. Penyajian media bersih, berwarna menarik dan proporsional. & 3 & 3 \\
\hline 3. Media dapat menarik minat peserta didik untuk belajar. & 3 & 3 \\
\hline $\begin{array}{l}\text { 4. Kesesuaian media dengan karakteristik serta kebutuhan peserta } \\
\text { didik. }\end{array}$ & 4 & 4 \\
\hline 5. Media yang digunakan relevan dengan topik yang diajarkan & 4 & 4 \\
\hline 6. Kesesuaian media terhadap tujuan yang diharapkan. & 4 & 4 \\
\hline 7. Media praktis dan luwes saat digunakan dalam pembelajaran & 4 & 4 \\
\hline 8. Media dapat digunakan secara berulang-ulang & 4 & 4 \\
\hline 9. Media memiliki kualitas yang baik & 3 & 3 \\
\hline 10. Mudah dibawa dan disimpan. & 4 & 4 \\
\hline & 35 & 36 \\
\hline
\end{tabular}

Validasi media sebagaimana Tabel 3.2 menunjukkan bahwa pada validasi pertama yaitu dengan $R=\frac{35}{1(10)}=3,5$. Hasil validasi materi ini dapat dikatakan bahwa media berada pada kriteria sangat valid.Akan tetapi ada point penilaian yang masih mendapatkan nilai dibawa rata-rata yakni pada descriptor pertama media dirasakan kurang rapi dalam susuan dan penataannya sehingga perlu diperbaiki dan dilakukan validasi kembali. Pada validasi kedua, diperoleh nilai dengan $R=\frac{36}{1(10)}=3,6$, dengan kategori sangat valid. Hasil ini menunjukan bahwa produk media berupa Aplikasi Android Berbasis Appypie sudah dapat digunakan.

\section{Kepraktisan Media}


Produk yang telah divalidasi dan dinyatakan layak untuk diujicobakan, selanjutnya diuji cobakan pada subjek uji coba kelompok kecil yaitu mahasiswa yang telah mengontrak matakuliah Taksonomi Monera dan Protista.Mahaiswa diminta untuk mempelajari media aplikasi android yang sebelumnya sudah diinstal pada handphone masing-masing.Setelah selesai mahasiswa diminta untukmengisi angket respon mahasiswa tehdapa produk media aplikasi android berbasis Appypie yang telah dikembangkan. Adapun tingkat kepraktisan media yang dilihat dari hasil respon mahasiswa setelah menggunakan media aplikasi android berbasis Appypie sebagai berikut:

Tabel 3.3 Hasil Angket Respon Siswa

\begin{tabular}{|c|c|c|c|c|c|c|c|c|c|c|c|c|c|c|c|}
\hline & Inisial & \multicolumn{10}{|c|}{ No. } & Mahasis \\
wa & & $\mathbf{1}$ & $\mathbf{2}$ & $\mathbf{3}$ & $\mathbf{4}$ & $\mathbf{5}$ & $\mathbf{6}$ & $\mathbf{7}$ & $\mathbf{8}$ & $\mathbf{9}$ & $\mathbf{1 0}$ & $\mathbf{1 1}$ & $\mathbf{1 2}$ & Jumlah & \multirow{2}{*}{$\begin{array}{c}\text { Rata- } \\
\text { rata }\end{array}$} \\
\hline 1 & MY & 4 & 4 & 4 & 3 & 4 & 4 & 3 & 4 & 4 & 4 & 4 & 4 & 46 & 3,83 \\
\hline 2 & ASM & 4 & 3 & 4 & 4 & 4 & 4 & 4 & 4 & 4 & 4 & 4 & 4 & 47 & 3,92 \\
\hline 3 & LH & 4 & 4 & 4 & 4 & 4 & 4 & 4 & 4 & 3 & 4 & 4 & 4 & 47 & 3,92 \\
\hline 4 & AI & 3 & 3 & 3 & 4 & 3 & 4 & 4 & 4 & 4 & 4 & 4 & 4 & 44 & 3,67 \\
\hline 5 & MEW & 4 & 4 & 3 & 3 & 3 & 3 & 3 & 3 & 3 & 4 & 3 & 3 & 39 & 3,25 \\
\hline 6 & RAP & 4 & 3 & 4 & 4 & 4 & 4 & 4 & 4 & 4 & 4 & 4 & 3 & 46 & 3,83 \\
\hline \multicolumn{11}{|c|}{ Rata-rata } \\
\hline
\end{tabular}

Berdasarkan Tabel 3.3 dapat diketahui bahwa respon mahasiswa terhadap media aplikasi berbasis appypie yang dikembangkan dengan pencapaian rata-rata 3,74 yang termasuk dalam kategori sangat praktis.

\section{KESIMPULAN DAN SARAN}

\section{a. Kesimpulan}

Berdasarkan hasil penelitian dan pengembangan aplikasi android berbasis appypie sebagai media pembelajaran taksonomi monera dan protista materi alga bagi mahasiswa pendidikan biologi dapat disimpulkan :

1. Pengembangan media aplikasi android berbasis appypie sebagai media pembelajaran taksonomi monera dan protista materi alga menggunakan model pengembangan DDD-E dengan 4 tahap pengembangan yaitu decide, design, develop dan evaluate.

2. Media aplikasi android berbasis appypie sebagai media pembelajaran taksonomi monera dan protista materi alga memenuhi kelayakan untuk digunakan dalam proses pembelajaran dengan tingkat kevalidan dari validasi materi 3,78 (sangat valid) dan tingkat kevalidan dari validasi media 3,6 (sangat valid) serta tingkat kepraktisan media dengan dengan nilai 3,74 (sangat praktis).

\section{b. Saran}

1. Penelitian dan pengembangan selanjutnya agar dapat mengembangkan media pembelajaran pada materi yang lainnya, sesuai dengan kompetensi dasar yang diajarkan. 
2. Pengembangan media aplikasi android hendaknya memperhatikan kemampuan smartphone yang digunakan oleh penggunaa aplikasi android dengan spesifikasi RAM $1 \mathrm{~Gb}$, OS v4.2.2 (Jelly Bean) ke atas, dan jaringan HSPA.

3. Penggunaan aplikasi android harus memperhatikan koneksi internet yang kuat agar data di operasikan.

\section{DAFTAR RUJUKAN}

Amin.A.K., dan Mayasari. N. (2015). Pengembangan media pembelajaran berbentuk aplikasi android berbasis weblog untuk meningkatkan hasil belajar mahasiswa pendidikan matematika IKIP PGRI Bojonegoro. Jurnal Magistra. 2 (2).

Asyhar, R. (2012). Kreatif mengembangkan media pembelajaran. Jakarta : Refernsi Jakarta

Intania. (2012). Sekali baca langsung inget mengupas lengkap all about android.Jakarta: Kunci Komunikasi

Muliyardi. (2006). Pengembangan model pembelajaran matematika menggunakan komik di kelas 1 $S D$. Disertasi tidak diterbitkan. Surabaya: Universitas Negeri Surabaya

Putra, N. (2012). Research and development, penelitian dan pengembangan: suatu pengantar. Jakarta: Raja Grafindo Persada.

Riduwan. (2013). Skala pengukuran variabel - variabel penelitian. Bandung : Alfabeta

Salbino, S. (2014). Buku Pintar Gadget Android.Jakarta : Kunci Komunikasi

Susuilana, R. (2009). Media Pembelajaran. Bandung : CV Wacana Prima

Tegeh, M,. Jampel, I.N, \& Pudjawan, K. (2014). Model penelitian pengembangan. Yogyakarta: Graha Ilmu

Widjajanti. (2008). Teknik-Teknik Penyusunan Soal Test. Bandung: PT. Remaja Rosda Karya 